\title{
Corrigindo as potenciais disfunções do sistema de proteção de desenho industrial
}

Corrigir as disfunções, como o título se propõe, presume que haja uma função. $\mathrm{Na}$ proporção em que tal função seja servida, e eficientemente, a norma jurídica estará sendo servida; de outro lado, se os poderes jurídicos destinados a implementar essa função estão sendo usados para outros propósitos, pode ser necessário a atuação de mecanismos jurídicos já existentes para assegurar a entropia do sistema, ou a modificação do sistema para fazê-lo mais eficiente.

Não basta que o instituto esteja servindo uma função jurídica. Para não haver disfunção, é preciso que se esteja implementando $a$ função jurídica própria do direito pertinente. Dissemos, em nosso Tratado, vol. I, cap. I, [4]§3:

Assim, ao conferir uma exclusiva àquele que detém legitimamente o bem incorpóreo, segundo os requisitos do sistema de proteção específico, o direito funcionaliza aquele bem incorpóreo. Lembre-se que não nos referimos, aqui, à funcionalização genérica das propriedades sob a Constituição, mas à especificação funcional de cada modelo, no seu desenho constitucional. (...)

O bem incorpóreo em que consiste em uma certa imagem de uma concha funciona como marca da Shell; mas o bem incorpóreo subsiste fora desta funcionalidade, e livre da exclusividade, por exemplo, como referencial para o direito constitucional de expressão.

De outro lado, um mesmo bem incorpóreo pode ser funcionalizado por diferentes exclusivas. Um bem incorpóreo (por exemplo, uma pintura) pode ser funcionalizada em face das condicionantes do direito autoral, e receber outra funcionalidade pela exclusiva de desenho industrial. Enquanto funcionando como desenho industrial, estará sujeito aos requisitos legais e constitucionais desse modelo; enquanto funcionando no campo e para os efeitos da exclusiva autoral, estará sujeito a outros requisitos e limites.

Quando tal se dá, tem-se que levar em conta as peculiaridades e sistemas, e construir-se um complexo sistema de compatibilidades, para evitar colisão entre os modelos funcionais. Não se pode usar um bem incorpóreo na função de marca, se o desenho constitucional reservado a esse bem incorpóreo é o de patentes. Quando há mais de uma exclusividade possível para um certo bem incorpóreo, 
é necessário verificar-se a minuciosa satisfação de seus requisitos de aplicação, para evitar-se que uma propriedade frustre a função da outra.

A função dos desenhos ornamentais, como visto, é primaria, ainda que não exclusivamente, a de permitir a diferenciação de produtos no mercado através da incorporação de um elemento acessório ornamental intrínseco ao corpus mechanicum.

Para o exercício eficaz dessa função, o direito concede uma panóplia de poderes ao seu titular, e especialmente a exclusividade, que se traduz num monopólio de fabricação e comercialização do produto ornamentado. Aí está o par: a função, e os poderes.

$\mathrm{Na}$ comparação entre os vários direitos de propriedade intelectual, o desenho industrial talvez seja aquele em que o equilíbrio entre as funções e os poderes jurídicos seja mais frágil. As patentes justificam um monopólio em troca de um investimento em novos conhecimentos tecnológicos, e da divulgação desse conhecimento muito antes do fim do direito exclusivo. As marcas tem, classicamente, uma função de minorar a assimetria de informações, a par de assegurar ao titular a identificação da origem dos produtos e serviços. A fruição das obras expressivas, continuamente renovadas, justifica abstratamente a exclusiva autoral.

O desenho industrial, não há dúvida, torna mais prazerosos os objetos de consumo, e em alguma forma introduzem no cotidiano a harmonia e a presença da criação humana. Comparativamente, no entanto, parece justificar menos os poderes jurídicos correlativos; a consequência mais clara da reserva legal, que é evitar a confusão do público quanto à origem dos produtos, poderia ser desincumbida pela concorrência desleal. E a permanência e relativo sucesso do modelo britânico de desenho industrial não registrado (e sem exclusiva) reforça essa noção.

Assim é que o número de contrapesos e moderações dos poderes jurídicos relativos aos desenhos industriais introduzidos homologicamente no próprio subsistema das normas de desenho industrial tem parecido crescer nos últimos anos.

Nesta seção, examinaremos dois temas de relevância para o problema em análise:

1. A questão da interconexão de sistemas

2. A questão das peças must match.

$\mathrm{Na}$ seção seguinte nos dedicaremos à análise da proteção de produtos complexos. 


\section{- O Problema da interconexão de sistemas}

Lê-se na Lei 9.609/98:

Art. $6^{\circ}$ Não constituem ofensa aos direitos do titular de programa de computador:

(...) IV - a integração de um programa, mantendo-se suas características essenciais, a um sistema aplicativo ou operacional, tecnicamente indispensável às necessidades do usuário, desde que para o uso exclusivo de quem a promoveu.

Notei, a respeito disso (Tratado, vol. III):

\section{[ 2 ] § 6. 6. - A integração de programa}

A fórmula desta limitação visa assegurar a integração de um programa, mantendo-se suas características essenciais, a um sistema aplicativo ou operacional, tecnicamente indispensável às necessidades do usuário, desde que para o uso exclusivo de quem a promoveu. Assim, utilizam-se as informações e a tradução do programa de forma que se possibilite a interoperabilidade dele com outro, independentemente de autorização do titular $\mathbf{1}$.

A lei faculta tais atos quando a interoperabilidade atende as necessidades pessoais do beneficiário: "tecnicamente indispensável às necessidades do usuário, desde que para o uso exclusivo de quem a promoveu". Não cabe a limitação quando a interoporabilidade se dá para uso no comércio, já pela regra convencional de que não se pode interferir no uso normal do programa, vale dizer, competir com o titular. O direito comparado aponta para os parâmetros de razoabilidade dessa limitação ${ }^{2}$.

Não nos é possível dar interpretação restritiva a esta limitação, como a nenhuma outra. Com José Oliveira Ascensão, entendo que "a descompilação é livre no direito brasileiro", se e quando indispensável para os propósitos da integração ${ }^{3}$.

1 Claramente se recusa aqui o preceito da lei geral autoral: “Art. 33. Ninguém pode reproduzir obra que não pertença ao domínio público, a pretexto de anotá-la, comentá-la ou melhorá-la, sem permissão do autor”.

2 Art. 122-6-1, V. La reproduction du code du logiciel ou la traduction de la forme de ce code n'est pas soumise à l'autorisation de l'auteur lorsque la reproduction ou la traduction au sens du $1^{\circ}$. ou du $2^{\circ}$. de l'article L.122-6 est indispensable pour obtenir les informations nécessaires à l'interopérabilité d'un logiciel créé de façon indépendante avec d'autres logiciels, sous réserve que soient réunies les conditions suivantes: $1^{\circ}$ Ces actes sont accomplis par la personne ayant le droit d'utiliser un exemplaire du logiciel ou pour son compte par une personne habilitée à cette fin; $2^{\circ}$ Les informations nécessaires à l'interopérabilité n'ont pas déjà été rendues facilement et rapidement accessibles aux personnes mentionnées au $1^{\circ}$ ci-dessus; $3^{\circ}$ Et ces actes sont limités aux parties du logiciel d'origine nécessaires à cette interopérabilité.Les informations ainsi obtenues ne peuvent être: $1^{\circ} \mathrm{Ni}$ utilisées à des fins autres que la réalisation de l'interopérabilité du logiciel créé de façon indépendante; $2^{\circ} \mathrm{Ni}$ communiquées à des tiers sauf si cela est nécessaire à l'interopérabilité du logiciel créé de façon indépendante; $3^{\circ} \mathrm{Ni}$ utilisées pour la mise au point, la production ou la commercialisation d'un logiciel dont l'expression est substantiellement similaire ou pour tout autre acte portant atteinte au droit d'auteur.

3 ASCENSÃO, José de Oliveira. Direito autoral. 2. ed. ref. e ampl. Rio de Janeiro: Renovar, 1997. p. 671 "Não encontramos referência expressa a esta matéria na lei brasileira. Mas o art. 7 IV permite 'a integração de um programa, mantendo-se as suas características operacionais, a um sistema aplicativo ou operacional, tecnicamente indispensável às 
A origem remota dessa disposição seria o projeto elaborado em 1985 para nossa primeira lei de software ${ }^{4}$, em que o tema da integração do programa foi discutido à luz do pleito concorrencial discutido no sistema europeu na década anterior, tendo como objeto o uso de direitos e de configurações técnicas utilizadas pela IBM para impedir a interconexão com periféricos de fabricação ou programação de terceiros ${ }^{5}$.

Assim, há pelo menos neste diploma legislativo brasileiro a previsão de que o direito exclusivo não pode impedir a interconexão de sistemas, quando se mostrar razoável do ponto de vista jurídico e eficiente na perspectiva econômica ${ }^{6}$. Mas no capítulo próprio da norma de desenhos industriais não há uma previsão específica ${ }^{7}$

Uma série de sistemas jurídicos incorporaram às normas de proteção dos desenhos industriais regras que excepcionam a exclusividade resultante da proteção, de jeito que não obstante a tutela do ornamento persista válida e eficaz, ela não possa ser

usuário, desde que para uso exclusivo de quem a promoveu'. Diretamente, autoriza-se uma adaptação, portanto uma transformação do programa. Mas esta pressupõe a descompilação. Na falta de preceito especial, devemos concluir que a descompilação é livre no direito brasileiro".

4 Por este subscritor, representando o INPI, Manoel J. Pereira dos Santos, pelo Conselho Nacional de Direitos Autorais e Raymundo de Noronha, pela Secretaria Especial de Informática. Vide tal proposta, Projeto de Lei Do Senado 260 De 1984, encontrado em http://www.denisbarbosa.addr.com/arquivos/historia/software1984.pdf. O dispositivo em questão foi resultado das discussões de classe sobre o caso europeu da IBM no curso Computer Law do mestrado da Columbia Law School em 1983. A redação do projeto inicial era: “Art.32. Não será negada autorização para produção de programa derivado que se destine à implantação em máquinas automáticas de tratamento de informação, de fabricação nacional, industrializadas por fabricantes diversos, com o objetivo de compatibilizá-las entre si ou com máquinas produzidas no exterior, em uso corrente no País".

5 "The European Commission's investigation of IBM during the early 1980s also emphasized bundling and nondisclosure of interface information. Beginning in the late 1960s, IBM experienced increasing competition from "plugcompatible" manufacturers (PCMs). Some like Telex, Memorex, and StorageTek built peripheral equipment such as tape storage drives, disc drives, and add-on memory units that plugged into the standard interfaces used on IBM System 360 and then System 370 mainframes. Others such as Amdahl (founded by the principal designer of IBM's System 360), Fujitsu, and IPL Systems, produced main frames (i.e., central processing units) that could be used interchangeably with IBM computers, but offered higher performance and/or lower cost. To combat these threats, IBM among other things began bundling peripheral equipment control functions into mainframe hardware. It also departed from what had previously been a full disclosure policy, keeping operating system software source code secret, reducing the amount of information disclosed on interface specifications, and delaying interface disclosures until they came too late to be of use by PCMs trying to design compatible equipment. In response to complaints by several American computer manufacturers, the European Commission's competition policy directorate commenced an investigation of IBM's bundling and disclosure policies.(...) The Europeans persisted, however, and were on the verge of issuing a formal complaint when IBM agreed in August 1984 to an "undertaking" accepted tentatively by the EC in lieu of an official mandate." Encontrado em http://www.antitrustinstitute.org/ antitrust/node/10374, visitado em 1/2/2013.

6 O exemplo desse dispositivo, aliás, à luz da interpretação dada pelo STJ, Resp 964.404 - ES (2007.0144450-5), Terceira Turma do Superior Tribunal de Justiça, por unanimidade, Ministro Paulo de Tarso Sanseverino, 15 de março de 2011 à categoria das limitações ("Ora, se as limitações de que tratam os arts. 46, 47 e 48 da Lei 9.610/98 representam a valorização, pelo legislador ordinário, de direitos e garantias fundamentais frente ao direito à propriedade autoral, também um direito fundamental (art. $5^{\circ}$, XXVII, da CF), constituindo elas -as limitações dos arts. 46, 47 e 48 - o resultado da ponderação destes valores em determinadas situações, não se pode considerá-las a totalidade das limitações existentes") poderia ser considerado para moderar alguns dos poderes de outros direitos da Propriedade Intelectual nos quais a integração entre sistemas e interfaces é relevante, sempre sob o filtro da eficiência e razoabilidade. A aplicação de uma limitação existente no sistema de marcas para aplicar ao mesmo conflito de interesses existente em outros direitos foi, aliás, a proposta contida para o direito relativo aos desenhos industriais em nosso artigo precitado, publicado na Revista Eletrônica do IBPI, número especial.

$7 \mathrm{Em}$ texto mais recente, BARBOSA, Denis Borges, Da indisponibilidade privada das limitações (2012), em http://www.denisbarbosa.addr.com/arquivos/200/propriedade/da_indisponibilidade_privada_limitacoes.pdf, 
usada como impedimento para interconectar sistemas ${ }^{8}$. Ou seja, os poderes da exclusiva são inoponíveis a esse tipo de uso específico.

Assim, os eventuais elementos ornamentais apostos numa tomada podem ser reproduzidos livremente na proporção em que isso seja necessário para que qualquer um possa fabricar e vender os plugs pertinentes, que estejam em domínio público ou sob outro direito de propriedade intelectual 9

Alguns autores enfatizam que essa limitação aos direitos de desenho industrial representa uma aplicação singular do princípio que exclui da proteção dos desenhos industriais a manifestação técnica; na verdade, o problema é mais de uma função técnica (a interconexão) do que da tecnicidade intrínseca ao produto ornamentado ${ }^{10}$.

\section{- Da questão das partes de reposição}

O problema singular das peças de reposição em produtos complexos dotados de proteção ornamental é distinto dos mencionados anteriormente e singular. Diz Miguel Moura e Silva ${ }^{11}$

Sinteticamente, o problema reside nos efeitos que resultam de cumular a protecção do desenho de um veículo automóvel com a protecção do desenho de cada um dos seus componentes, pelo menos no que respeita àqueles que preenchem individualmente os requisitos de protecção.

Assim analisamos a questão recentemente ${ }^{\mathbf{1 2}}$ :

O resguardo da competição nos mercados de peças e serviços de reposição.

\footnotetext{
8 "The 'must fit' exception - The other important exception for non-aesthetical features from the scope of registered designs is the 'must fit' exception, which deals with a type of functional design features. Section $1 \mathrm{C}(2)$ [o autor refere-se à Diretriz Européia] defines the scope of the exception in the following way: "A right in a registered design shall not subsist in features of appearance of a product which must necessarily be reproduced in their exact form and dimensions so as to permit the product in which the design is incorporated or to which it is applied to be mechanically connected to, or placed in, around or against, another product so that either product may perform its function"... Clear examples in practice are electrical plugs and sockets, connectors for lamps to fit into sockets, and batteries to fit into watches. In all of these cases, there is a need for the features of appearance to be reproduced in their exact form and dimensions, and this necessity for exact reproduction is therefore the key element in the exception." TORREMANS, Paul. Intellectual Property Law. 6Th Edition. Ed. Oxford New York: University Press. 2010. P. 343-349 e 355-456.

9 "Clear examples in practice are electrical plugs and sockets, connectors for lamps to fit into sockets, and batteries to fit into watches. In all of these cases, there is a need for the features of appearance to be reproduced in their exact form and dimensions, and this necessity for exact reproduction is therefore the key element in the exception." Id.

10 "This exception is clearly very similar to the technical function exception and there could arguably be an overlap. In fairness to the drafters of the legislation, it can be said that the technical function exception primarily deals with a product that works on its own and in relation to which the design features are dictated by the technical function of that product, whereas the 'must fit' exception deals with two products that need to be connected, etc., in order for them to work. Rather than a technical, this is more a functional exception." Id.

11 SILVA, Miguel Moura e. Desenhos e Modelos Industriais- Um Paradigma Perdido? in Associação Portuguesa de Direito Intelectual. Direito Industrial vol. I. Almedina: Coimbra, 2001. pp. 438-440, 443-446. Ainda sobre o regime europeu, vide DURIE, Robyn. European Community Design Law, p. 78-103. In GRAY, Brian W., BOUZALAS, Effie (ed.). Industrial Design Rights An International Perspective. Londres: Kluwer Law International, 2001

12 BARBOSA, Denis Borges, A proteção dos mercados secundários no direito da propriedade intelectual no Brasil, Revista Eletrônica do IBPI: Sobre a questão das peças de reposição must-match, Edição Especial Janeiro de 2010, Encontrada em http://www.wogf4yv1u.homepage.tonline.de/media/b1f03417495d4142ffff831aac144220.pdf, visitada em 13/10/2010.
} 
O Código da Propriedade Intelectual da França assim dispõe:

Art. L. 713-6 L'enregistrement d'une marque ne fait pas obstacle à l'utilisation du même signe ou d'un signe similaire comme :(..)

b) Référence nécessaire pour indiquer la destination d'un produit ou d'un service, notamment en tant qu'accessoire ou pièce détachée, à condition qu'il n'y ait pas de confusion dans leur origine.

Toutefois, si cette utilisation porte atteinte à ses droits, le titulaire de l'enregistrement peut demander qu'elle soit limitée ou interdite.

Assim, o registro da marca não impede, naquele direito, que terceiros façam uso dela para indicar a destinação de um produto ou de um serviço, quando tal uso seja necessário para a comercialização do item, especialmente se é um acessório ou peça destacada do bem ao qual se destina.

A jurisprudência 13 e a doutrina 14 apontam para a importância dessa disposição, no que faculta a concorrência de produtores independentes das peças e serviços.

A Corte de Justiça Europeia analisou caso desta natureza, à luz da legislação europeia, no qual o titular da marca BMW desejava impedir que uma oficina de revenda e conserto utilizasse tal signo distintivo para promover seus produtos e serviços. Tal pedido foi julgado improcedente e a Corte garantiu à oficina o direito de usar marca alheia, mesmo sem o consentimento do seu titular 15.

Nesta perspectiva, diz Karin Grau-Kuntz ${ }^{\mathbf{1 6}}$ :

A questão que envolve, por um lado, o direito exclusivo das montadoras de veículos que registram como desenhos industriais peças externas que compõem seus automóveis e, por outro lado, o

\footnotetext{
13 Vide, caudalosamente, os julgados recolhidos em Code de La Propriété Intellectuelle, Dalloz, 8 $8^{\text {a }}$ Ed., $\backslash$ 2009, p. 619 e seguintes.

14 Por exemplo, POLLAUD-DulLIAN. Frédéric, Droit La Propriété Industriele, Montchrestien, 1999, p. 612 e seguintes.

15 Acórdão do Tribunal de 23 de Fevereiro de 1999. - Bayerische Motorenwerke AG (BMW) e BMW Nederland BV contra Ronald Karel Deenik. - Pedido de decisão prejudicial: Hoge Raad - Países Baixos. - Directiva sobre as marcas - Uso não autorizado da marca BMW nos anúncios de um garagista. - Processo C-63/97, “64. Face ao que precede, há que responder às quarta e quinta questões que os artigos 5._e 7._ da directiva não permitem ao titular de uma marca proibir a um terceiro o uso da sua marca para anunciar ao público que efectua a reparação e a manutenção de produtos desta marca comercializados sob a marca pelo seu titular ou com o seu consentimento ou que é especializado ou especialista na venda ou na reparação e na manutenção de tais produtos, a não ser que a marca seja utilizada de um modo tal que possa dar a impressão de que existe uma relação comercial entre a empresa terceira e o titular da marca e, nomeadamente, que a empresa do revendedor pertence à rede de distribuição do titular da marca ou que existe uma relação especial entre as duas empresas". Encontrado em http://eurlex.europa.eu/LexUriServ/LexUriServ.do?uri=CELEX:61997J0063:PT:HTML, visitado em 3/1/2010
}

16 GRAU-KUNTZ, Karin, Sobre o desenho industrial e a proteção das peças de reposição de automóveis, encontrado em http://www.migalhas.com.br/mostra_noticia_articuladas.aspx?cod=89666 
controle do mercado de peças de reposição, trata exatamente da "equação da legitimação".

Não se trata aqui de proteção garantida às peças de automóveis consideradas como parte integrante do automóvel, e no momento da montagem do veículo, mas sim de peças protegidas por uma exclusividade em um momento posterior, quando elas são vendidas em avulso, pressupondo-se que o consumidor já tenha adquirido o veículo, a fim de que venham a ser utilizadas para repor uma peça defeituosa ou danificada.

Os automóveis se distinguem, em suas aparências, pelos detalhes de suas partes visíveis. Presume-se que o consumidor, quando prefere um modelo em detrimento de outro, tome sua decisão também levando em consideração a aparência do automóvel. A preferência do consumidor por um modelo em relação a outro supõe possibilidade de escolha, do que resulta estimulada a concorrência, que é concebida como fator gerador de bem-estar social. Daí justificarse a proteção de peças que compõem modelos de veículos, desde que preencham determinados requisitos, pelo desenho industrial.

No sistema regional europeu, tem-se duas soluções normativas para esse problema ${ }^{17}$ : no Regulamento do registro regional, exclui-se a proteção para essa hipótese ${ }^{18}$. Mas, como nota Miguel Moura e Silva, a solução da Diretiva Europeia de harmonização das leis nacionais foi outra:

O compromisso que vingou na Directiva consiste num misto de justiça salomónica e de non liquet. Por um lado é permitida a protecção dos componentes, sujeita embora a duas condições:

- se, depois de incorporado, o componente continuar visível durante a utilização normal do produto complexo e,

- na medida em que as próprias características visiveis do componente preencham os requisitos de protecção.

O conceito de utilização normal, contido no artigo $3^{\circ}$, $\mathrm{n}^{\circ} 4$, exclui os componentes cujo desenho ou modelo normalmente não desempenha qualquer papel para o

\footnotetext{
17 Há a norma que institui um registro de desenhos ao nível regional (Regulamento do Conselho (EC) nº 6/2002 de 12 de dezembro $2001, \quad$ de encontrado $\quad$ em http://oami.europa.eu/ows/rw/resource/documents/RCD/regulations/62002_en_cv.pdf), e outra norma visando a harmonização das leis nacionais de desenho industrial (Diretiva 98/71/EC), encontrada aqui http://eurlex.europa.eu/LexUriServ/LexUriServ.do?uri=CELEX:31998L0071:EN:HTML.

18 Para o estado das propostas legislativas em curso em outros sistemas jurídicos, e maior detalhamento da questão econômica em questão, vide o nosso Da nossa proposta de mudança das normas brasileiras relativas aos desenhos industriais, em http://www.denisbarbosa.addr.com/arquivos/200/propriedade/proposta mudanca normas brasileiras di.p df.
} 
consumidor, uma vez que só são visíveis durante a reparação ou manutenção. ${ }^{19}$

O problema, que é objetivo e geral e terá soluções normativas, regulatórias ou judiciais, conforme o sistema jurídico, passa pelo uso dos poderes de exclusão inerentes aos privilégios de desenho industrial para prevenir que terceiros fabriquem e vendam peças de reposição em geral (não só de automóveis, como faz entender a citação acima), quando tais peças sejam ornamentadas e protegidas pela lei pertinente.

Note-se que o problema de política público é diverso, e não pode ser assimilado à questão da tecnicidade ou da interconexão de sistemas. Embora as partes de reposição necessariamente interconectem, não é quanto à essa função que o problema ocorre, mas quanto à integralidade visual do bem complexo ao qual a reposição conecta.

É sim um elemento ornamental e não técnico que cria o problema de política

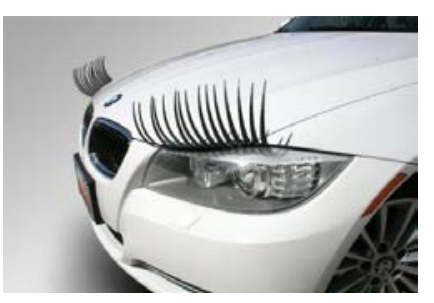
pública. Ainda que uma peça de reposição interconecte-se perfeitamente, se não seguir o mesmo padrão ornamental do produto complexo haverá provavelmente perda da galanteria, diminuição do efeito vebleniano e redução de um valor de revenda. Essas consequências não serão logicamente necessárias, pois soluções ornamentais não infringentes do desenho registrado podem ser teoricamente encontradas, obtendo efeitos de todo que não comprometam necessariamente a estética ou vendabilidade do produto complexo (como os acessórios consistindo em pestanas para os faróis, em moda, modificam o efeito total do design) ${ }^{20}$.

Assim, não é uma questão estrutural do sistema de propriedade intelectual, mas relativa ao uso adequado ou impróprio dos poderes legais resultantes dos privilégios no tocante ao exercício dos direitos ${ }^{21}$. Qualquer impacto negativo potencial desse efeito das exclusivas ornamentais poderia ser evitado, por

19 O considerando 12 do preâmbulo da Directiva esclarece que ass características do desenho ou modelo excluídas da protecção por serem invisíveis quando o componente se encontra montado ou por não satisfazerem os requisitos de novidade e carácter singular não devem ser tomadas em consideração para apreciar se outras características preenchem aqueles requisitos.

20 Sobre este aspecto, vide abaixo a distinção entre dependência e subsidiariedade, a que se referem BENTLY, Lionel. SERMAN, Brad. Intellectual Property Law. Oxford University Press: New York, 2004 no tocante à norma britânica de desenhos registrados. As pestanas são subsidiárias, e não integrariam o estatuto especial da exceção must match.

21 A decisão do CADE de 15 de dezembro 2010 na Averiguação Preliminar No 08012.002673/2007-51 evidencia que não existe nenhum problema estrutural do sistema de propriedade intelectual no tocante às peças de reposição. Ao contrário, a decisão fez retornar ao órgão de investigação o feito para ver se na materialidade do caso, havia alguma infração real dos dispositivos indicados. "260. Diante disso, voto pelo provimento do recurso de ofício, com o consequente retorno dos autos à SDE para a instauração de Processo Administrativo, nos termos aqui colocados, a fim de apurar possível violação, pelas Representadas, aos arts.20, incisos I, II e IV, e 21 incisos IV e V, da Lei no 8.884/94, no setor de autopeças de reposição. 261. Conforme a análise aqui empreendida, sugere-se que a SDE pondere e, se possível, levante dados que embasem ou, eventualmente, rechacem os argumentos aqui levantados, sem prejuízo de exames adicionais que tenha por bem aprofundar, tudo dentro de seu juízo de conveniência e oportunidade". 


\title{
exemplo, por estruturas de preços que não fizessem uso desrazoável dos poderes legais, ou políticas de licenciamento RAND adequadas ${ }^{22}$.
}

\begin{abstract}
A opção de introjectar na normativa de propriedade intelectual europeia mecanismos que tratam dessa questão abstratamente, e não casuisticamente, foi decisão de política legislativa no sistema regional ${ }^{23}$. A decisão dos órgãos da União Europeia resultou de acerba discussão política ${ }^{24}$, que inclusive superou decisões judiciais contrastantes ${ }^{25}$.
\end{abstract}

\begin{abstract}
22 "Esta aparente contradicción obliga a compatibilizar el ejercicio legítimo de los derechos de propiedad industrial con las normas que rigen la libre competencia. En el ámbito que nos ocupa, el Tribunal de Justicia de las Comunidades Europeas ha señalado que la negativa por parte de los fabricantes de automóviles a conceder licencias sobre los repuestos a los fabricantes independientes no constituye un abuso de posición dominante. No obstante, en la Sentencia de 5 de octubre de 1988 (caso Consorzio italiano y Maxicar v. Renault) el TJCE estimó que sí podrían constituir abuso otras conductas del titular entre las que se mencionan la negativa arbitraria a suministrar piezas de recambio a talleres de reparación independientes, la fijación de precios no equitativos o la decisión de no seguir produciendo piezas para un determinado modelo cuando sigan aún circulando muchos vehículos de dicho modelo. EL TJCE mantuvo esta misma doctrina en el caso Volvo AB v. Erik Veng Ltd." REIJA, Carmen Lence. La Protección Del Diseño En El Derecho Español. Madrid.: Marcial Pons. 2004. P.48-49 e 94-97

23 "A controversial issue is the protection afforded to 'must-match' parts, being parts that must be a particular shape to match the rest of a complex product of which it is a part. An example is a replacement wing for a motor vehicle or a replacement headlamp for a vehicle. Such spare parts are not protected by the Community design [Article 110(1) of the Community Design Regulation.] but the Directive harmonising design protection throughout the Community allowed Member States to retain their previous position on the protection of such parts provided that, if they made any changes, they could only liberalise the market [Proposal for a Directive of the European Parliament and of the Council amending Directive 981 7I/EC on the legal protection of designs COM (2004) 582 final, SEe (2004) 1097, 14.09.2004, P 5]. The main market affected was the aftermarket in spare parts for motor vehicles, estimated at $€ 7.5 \mathrm{bn}$ annually. Nine Member States, including the UK, denied protection for 'must-match' spare parts but the remaining 16 Member States have protection for such parts". BAINBRIDGE, David I. Intellectual Property. Reino Unido : Pearson Longman , 2006 6th ed. pp. 486-492, 545-553. A resposta da consulta referida pode ler-se em http://www.europanu.nl/id/vi7jgsymsdz3/proposal_for_a_directive_of_the_european. Diz MORALES, María Baylos (cord.). Tratado De Derecho Industrial. Thomson Reuters: Espanha, 3a ed. 2009. pp.1303-1307" Como resultado de ello, la Comisión Europea presentó en septiembre de 2004 la Propuesta de Directiva de modificación de la Directiva 98/71/CE, proponiendo reformar el artículo 14 de la primera Directiva en el sentido de no permitir la protección como diseño de las piezas de recambio en la Unión Europea. Tras una opinión favorable de la Comisión de Asuntos Legales del Parlamento Europeo, en noviembre de 2007 el propio Parlamento aprobó en primera lectura dicha propuesta, tras introducir algunos cambios: prolongar el régimen transitorio durante otros cinco años y garantizar que el consumidor estuviera adecuadamente informado sobre el origen de las piezas de recambio. Todo parece indicar que finalmente se aprobará esta modificación de la Directiva, que impondrá a los Estados miembros la liberalización del mercado de dichos componentes tras un nuevo período transitorio de cinco años." Até o momento em que se escreve este estudo, não houve aprovação pelo Parlamento da proposta de emenda.

24 "Pero intensas desavenencias imposibilitaron el acuerdo. Las diferencias estaban motivadas por dos factores: de una parte, las disparidades de las legislaciones de los miembros de la Unión Europea que dieron lugar a un debate polarizado en el que Alemania y Francia se mostraban contrarios a la liberalización, y el Reino Unido favorable. El segundo factor que propició la ruptura fueron las presiones de dos grupos: de un lado, el de los fabricantes de automóviles que, como es lógico, pretendían una protección plena de las piezas de recambio y, de otro, una alianza formada por los fabricantes independientes de recambios y las compañías aseguradoras, que son las principales perjudicadas por la protección." REIJA, Carmen Lence. La Protección Del Diseño En El Derecho Español. Madrid.: Marcial Pons. 2004. P.48-49 e $94-97$ 25 "Questa scelta di politica legislativa, ancorché non necessitata, è stata certamente favorita dalla scelta logicamente precedente di non più attribuire rilevanza alia "funzione ornamentale" degli oggetti suscettibili di registrazione come disegni o modelli. La scelta comunitaria ha ribaltato la tesi accolta dalla Suprema Corte italiana, che risolveva in favore delle imprese dei ricambisti independenti il conflitto che le opponeva alle case automobilistiche. Ed invero la Suprema Corte era pervenuta alla conclusione che le parti staccate delia carrozzeria di un'automobile (un parafango, un paraurto, ecc.) non erano idonei a colpire il senso estetico dell'osservatore, e perciò non erano suscettibili di valida brevettazione. Le case automobilistiche hanno fatto prevalere, nel corso dei lavori preparatori della direttiva, una solzione che - in linea di principio - è diametralmente opposta a quella fatta propria dalla Suprema Corte di Cassazione italiana". AUTERI, P., FLORIDIA, G., MANGINI, V. et al. Diritto Industriale- Proprietà E Concorrenza. Torino : G. Giappichelli Editore, $20084^{\text {a }}$ ed. pp. 305-306. Vide também sobre o direito italiano PAVANELLO, Luigi. Protection of Industrial Design Under Italian Law, p. 156. In GRAY, Brian W., BOUZALAS, Effie (ed.). Industrial Design Rights An International Perspective. Londres: Kluwer Law International, 2001.
\end{abstract}


Nenhuma discussão política ocorreu no Brasil, que legitimasse uma mudança normativa em qualquer dos dois sentidos das normas europeias, por decisão do Poder Legislativo, muito embora seja o entendimento deste subscritor que uma mudança seja necessária, e nem de longe só pela questão analisada nesta seção ${ }^{26}$. Temos, assim, que analisar e resolver esse problema nos termos de nossa lex data.

\section{Da política pública em relação aos produtos complexos}

Ambas as questões acimas discutidas passam, de alguma forma, pela noção de produtos complexos. O elemento ornamental é aplicado a um sintagma de produtos que venham a formar um todo funcional (must-fit) ou, de outro lado, o produto complexo é suscetível, em abstrato, de repartição em elementos componentes.

Quando não pode haver, segundo os princípios pertinentes, o tratamento de um produto complexo, sendo-lhe somente aplicável o regime de produto unitário ${ }^{27}$ ? A questão pode ser colocada de, pelo menos, três formas diversas:

1. Do ponto de vista da criação ornamental, haverá uma unitariedade de desenho ${ }^{28}$ que não poderá ser cindida se em prejuízo do efeito

26 Vide BARBOSA, Denis Borges, Da nossa proposta de mudança das normas brasileiras relativas aos desenhos industriais (2010), parte do estudo encomendado pela Secretaria Especial de Assuntos Estratégicos da Presidência da República em 2010, em http://www.denisbarbosa.addr.com/arquivos/200/propriedade/proposta_mudanca_normas_brasileiras_di.pdf. Para esse objeto específico, propusemos a seguinte mudança legislativa: "Art. 109-A - O disposto no caput do artigo anterior não se aplica: III - aos fabricantes de acessórios, implementos e peças de reposição de bens de consumo durável, que utilizem o objeto do desenho protegido exclusivamente para suprir a reposição, no interesse do consumidor, de parte integrante de produto já vendido, desde que obedecidas às práticas leais de concorrência e mantidas as especificações de qualidade do elemento original;" E se motiva tal inovação da seguinte forma: "Introduz-se um rol específico de limitações, adaptando-se a referência (imperfeita) que se faz ao sistema de patentes, e acrescentando a limitação às peças must-match. Esta exige que para manter a limitação, em benefício do consumidor e para garantir as condições de concorrência leal, o elemento reposto deverá ser equivalente qualitativo da peça original."

${ }^{27}$ Distingue-se aqui o regime da unidade de invento, segundo o qual para cada privilégio deva haver uma só criação, da questão da unitariedade do objeto, ou seja, que o produto ao qual se apõe o ornamento seja num só corpo. Quanto à unidade, parece interessante a noção da Summa: "Unitas autem motus secundum quam dicitur simpliciter unus, consistit in unitate omnium horum. Oportet enim id in quo est motus, esse unum et indivisibile, eo modo quo species specialissima indivisibilis dicitur." Thomas de Aquino, Commentaria, In libros Physicorum, 5, Lectio 6. Quanto à unitariedade, vide a definição do dicionário Houaiss: unitário adjetivo ( 1858) 1 que diz respeito à unidade (...) 3 que forma um todo organizado; que apresenta unidade < 0 homem deve almejar a um conhecimento u. >. Ou, numa outra perspectiva, Isaías, 48:12: Audi me, Iacob, et Israel, quem ego vocavi; ego, ego primus et ego novissimus. É unitário, mas não uno, o elemento suscetível de ser dividido, ainda que, juntas as partes, se tenha um todo, e cada uma dessas partes subsista, ainda que de uma outra forma, em si mesmo, preservando o potencial de voltarem a ser o todo complexo.

28 A questão da unitariedade do desenho encontra nota em doutrina já antiga. SYMONS, William Leonard. The Law Of Patents For Designs. Bibliolife: Washington, D.C.,1914. pp. 27-28, 32-33, "In the case of Graff, Washbourne \& Dunn v. Webster in holding a design patent for a border section of a dish valid some apparent force is given to the view that a fragment is patentable. In that case the court said it would seem that an inventor could patent some component detail of his design. The court may, however, have regarded the border section as an independent article of manufacture". Mais adiante: "Unity of design constitutes another very important question in design cases, and it may be laid down as a general rule that where there is no necessary connection between two designs or parts of a design, there is an absence of unity to render them a single patentable design." Embora pareça que o autora se refira ao requisite de unidade do desenho, logo em seguida fica claro que a questão é da unitariedade: "A cradle supporting frame and a cradle body were held not to be a unitary structure although used together. They were two separate designs". A mesma consideração se 
tutelado, por exemplo, se faltarem novidade e originalidade nas partes singulares, ainda que subsistam no todo.

2. Do ponto de vista da industrialidade, haverá unitariedade de produto, se for ele fabricado de uma só vez ou num só processo, de forma que a separação em partes singulares importará em fragmentação do objeto.

3. Do ponto de vista da usabilidade do produto, se o objeto chega ao consumo sempre e necessariamente unitário, a proteção ornamental de partes desse objeto, que não atendam ao requisito do efeito ornamental unitário de que se falava imediatamente acima.

A legislação de uma sem número de sistemas nacionais indica explicitamente que a proteção ornamental se aplica tanto a um todo como também - sob certas condições - às partes deste complexo ${ }^{29}$, ainda que os requisitos de proteção devam ser aplicáveis, singularmente, a tais elementos parciais.

O que será um produto complexo? Na definição da lei sueca, será aquele que, muito embora seja composto de múltiplos componentes substituíveis, possa ser desmontado e remontado ${ }^{30}$. Para a norma australiana o parâmetro de produto complexo é o formado de partes que são fabricadas separadamente ${ }^{31}$; a legislação de Bahamas acrescenta ....e vendidas separadamente ${ }^{32}$. A norma

nota na lei de Taiwan: YUN, Patrick \& LIU, Frank. Protection of Industrial Designs in Taiwan in a Nutshell, p. 264-265. In GRAY, Brian W., BOUZALAS, Effie (ed.). Industrial Design Rights An International Perspective. Londres: Kluwer Law International, 2001." In light of the Patent Office's stringent attitude towards the doctrine of "unity of design", it is worthy of consideration to disclose an embodiment of a single article in a design patent application, especially when the industrial design at issue has salient features in any aspect of shape, pattern and colour. This is also true for articles which show an absence of absolute or concrete association between them, for example, speakers and tuners, cups and teapots, sofas and tea tables, as well as cushions and chairs".

29 Assim é, no sistema jurídico Americano: "In Zahn [In re Zahn, 617 F.2d 261, 204 U.S.P.Q. 988 (CCPA 1980)], the court held that a part of an article, such as a drill bit shank, could be the subject of a design patent". CHISUM, Donald S. JACOBS, Michael A. Understanding intellectual property law. Matthew Bender \& Co., Inc. Editorial Offices. United States. 1995. P. 68[2]

30 "Design" is defined in the Swedish Design Protection Act as "the appearance of the whole or a part of a product resulting from the features of the details of the product or of the details of the ornamentation of the product, in particular as regards the lines, contours, colors, shapes, textures or materials." The term "product" is defined in the act as "any industrial or handicraft item, including parts intended to be assembled into a complex product, packaging, get-up, graphic symbols and typographic type-faces, but excluding computer programs." The term "complex product" is defined in the act as "a product which, through being composed of multiple replaceable components, can be disassembled and then reassembled." Thompson West. Designs and utility models throughout the world, v. 2. Thomson West. 2009. Na verdade, como notam, BENTLY, Lionel. SERMAN, Brad. Intellectual Property Law. Oxford University Press: New York, 2004. Pp.613-617, 635-636, 671-675tal redação reflete a Diretiva (Designs Dir., Art. I(e); RDA s. 1(3); CDR, Art. 3(e). Os autores dizem: "The British implementation of Art. I(e) of the Directive, contained in s. 1(3) of the amended Act, redefined 'complex product' to mean 'a product which is composed of at least two replaceable component parts permitting disassembly and reassembly of the product'."

31 Australia, "Article" is any article of manufacture and includes part of an article if made separately. Thompson west. Designs and utility models throughout the world. Thomson West. 2009 - Vol. 1. Também GILCHRIST, Sue; ZIEGLER, Deborah, ROWE, Catherine. Industrial Design Law in Austrália, p. 15-16. In GRAY, Brian W., BOUZALAS, Effie (ed.). Industrial Design Rights An International Perspective. Londres: Kluwer Law International, 2001.

32 Bahamas, "Article" means any article of manufacture and includes any part of an article that is made and sold separately", "As used in that definition, "product" means any article manufactured by industry or handicraft, including parts intended to be assembled into a complex item, sets or compositions of items, packaging, fashion designs, graphic symbols and typographic typefaces.". idem. A mesma exigência se lê na lei indiana, segundo AHUJA, Sudhir. Protection of Industrial Design in India, p. 135-136. In GRAY, Brian W., BOUZALAS, Effie (ed.). Industrial Design Rights An International Perspective. Londres: Kluwer Law International, 2001. Ainda o mesmo na lei japonesa: ASAMURA, Kioshi 
alemã exige que o elemento a ser incorporado no produto complexo seja a todo tempo visível ${ }^{33}$.

Encontramos, nessa compilação das normas regionais e nacionais, assim, os pressupostos da proteção segregada dos elementos de um produto complexo; a observação da lei alemã (exemplo nem de longe isolado) traz ainda a compulsoriedade de que o elemento, que se pode agregar e desagregar do complexo, mantenha-se sempre em função ornamental, pois visível.

Há, se não uniformidade, uma convergência nas normas nacionais pertinentes neste sentido ${ }^{34}$.

Para a aplicação das regras relativas ao must-match, as normas tendem a acrescentar uma importantíssima qualificação: a relação entre o complexo e o componente deve regrar-se por uma relação de dependência no eixo da ornamentalidade, introduzindo, em certas normas nacionais, a noção de intenção de dependência ${ }^{35}$.

Desta maneira, a tendência dominante das legislações estudadas é permitir a proteção das partes isoladas de produtos complexos; e somente aplicar a exceção must match nos casos em que as configurações do produto complexo

\& OKANO, Mitsuo. Japanese Design Law: A summary for pratictioners of the protection system under the design law in Japan, p. 177. In GRAY, Brian W., BOUZALAS, Effie (ed.). Industrial Design Rights An International Perspective. Londres: Kluwer Law International, 2001...

33 "With respect to designs applied to or incorporated into a product which constitutes a component part of a complex product, such designs will only be considered to be new and to have individual character if the component part, once it has been incorporated into the complex product, remains visible during normal use of the product and only to the extent that those visible features of the component part fulfill in themselves the requirements of novelty and individual character." KLETT, Alexander R. SONNTAG, Matthias. WILSKE, Stephan. Intellectual Property Law In Germany. Verlag C.H. Beck: Munique, 2008. p.80. Também MICHAELI, Klaus Jurgen. Protection of Industrial Designs: An Overview of German Law. p. 123. In GRAY, Brian W., BOUZALAS, Effie (ed.). Industrial Design Rights An International Perspective. Londres: Kluwer Law International, 2001.

${ }^{34}$ Sobre o tratamento da questão em outros sistemas nacionais, vide SARTI, Davide. La Tutela Sull'estetica Del Prodotto Industriale - 118 Quaderni di Giurisprudenza Commerciale - Casa Editrice Giuffré. 1990. Milano. P. 141-145 BERTRAND, André. La Propriété Intellectuelle- Livre II Marques Et Brevets Dessins Et Modèle. Dilmas : Paris, 1995. pp. 35-38. MORALES, María Baylos (cord.). Tratado De Derecho Industrial. Thomson Reuters: Espanha, $3^{a}$ ed. 2009. pp.1303-1307. BIGARD, Stig, MADSEN, Klaus. Protection of Industrial Design in the Nordic Countries, p. 215-216. In GRAY, Brian W., BOUZALAS, Effie (ed.). Industrial Design Rights An International Perspective. Londres: Kluwer Law International, 2001. MIRANDAH, Gladys. Industrial Design Law in Singapore, p. 234-236. In GRAY, Brian W., BOUZALAS, Effie (ed.). Industrial Design Rights An International Perspective. Londres: Kluwer Law International, 2001. MIRANDAH, Gladys. Industrial Design Law in Singapore, p. 234-236. In GRAY, Brian W., BOUZALAS, Effie (ed.). Industrial Design Rights An International Perspective. Londres: Kluwer Law International, 2001.

35 "Section 213(3)(b )(ii) of the 1988 Act excludes from unregistered design right features of shape or configuration of an article which are dependent upon the appearance of another article of which the article is intended by the designer to form an integral part." BENTLY, Lionel. SERMAN, Brad. Intellectual Property Law. Oxford University Press: New York, 2004. Pp.613-617, 635-636, 671-675. Os autores se empenham em detalhar os aspectos da "aparência", da "dependência", do elemento dominante e do dependente, assim como o requisito intencional. Para os doutrinadores, por exemplo, há uma distinção entre "dependente" e subsidiário, dando o exemplo: "For example, a steering wheel may be replaced with an alternative wheel of a sportier design while leaving the general appearance of the vehicle unchanged. Likewise, an owner might choose to substitute seats with more comfortable seats. Although the owner of a car might wish the component to blend in with the general style of the vehicle, such items would not be dependent on the appearance of another article. This reflects the goal of the section which was to 'protect spare parts to the extent that they have features of shape and configuration which do not have to be copied in order to fit or to match aesthetically"'. Sobre o mesmo sistema jurídico, vide GARRET, John Linneker. The Law of Industrial Design in United Kindom.p. 298-300 In GRAY, Brian W., BOUZALAS, Effie (ed.). Industrial Design Rights An International Perspective. Londres: Kluwer Law International, 2001. 
crie, faticamente, uma relação de dependência das partes segregáveis, de forma que nas condições do mercado, a reposição ou reparo da parte segregada tenha de conformar-se inexorável à ornamentalidade do complexo.

Como já notamos, a falta de harmonização dos sistemas nacionais impede que se tome tais testemunhos como uma contribuição de direito comparado. $\mathrm{O}$ levantamento, porém, contribui eficazmente para determinar a recorrência dos problemas quanto ao ponto em análise, e o rol de soluções. É neste sentido que se trouxe estas considerações.

\section{Da questão dos produtos complexos no direito brasileiro vigente}

Nesta seção examinaremos especificamente o quesito:

1. se os objetos componentes de um todo maior são suscetíveis de proteção como desenhos industriais no direito brasileiro.

Do ponto em análise

O tema em discussão passa essencialmente por um entendimento do designer Frederico Cunha ${ }^{36}$, quanto à interpretação jurídica do seguinte dispositivo:

Art. 95. Considera-se desenho industrial a forma plástica ornamental de um objeto ou o conjunto ornamental de linhas e cores que possa ser aplicado a um produto, proporcionando resultado visual novo e original na sua configuração externa e que possa servir de tipo de fabricação industrial.

Leia-se a exegese:

"A condição de privilegiabilidade dessas partes de objetos como Registro de Desenho Industrial foi imediatamente questionada porque, na verdade, não se tratam de objetos em si, em sua forma integral e acabada, mas tão somente uma parte dos mesmos..." (p.129) (...)

“... a Lei, no seu Capítulo II, Seção I, que trata dos desenhos industriais registráveis em seu Art. 95, define como desenho industrial a forma plástica ornamental de um objeto e, portanto, não prevê proteção para partes de objetos, tal como é previsto para o caso do Modelo de Utilidade... 37" (p.129)(...)

"Portanto, pelo fato de não se tratar de um objeto em sua concepção integral, conforme sugerem os princípios da engenharia do produto industrial, como o conceito da "forma completamente definida", nesses

\footnotetext{
36 CUNHA, Frederico Carlos da. A proteção legal do design. Editora Lucerna. $2^{a}$ edição. Rio de Janeiro, 2003. 37 [Nota do original] De acordo com o Art. $9^{\circ}$ da Lei: É patenteado como modelo de utilidade o objeto de uso prático, ou parte deste, suscetível de aplicação industrial, que apresente nova forma ou disposição, envolvendo ato inventivo, que resulte em melhoria funcional no seu uso ou em sua fabricação.
} 
casos, logo após a publicação da concessão, devem ser instaurados os processos de nulidades de oficio para que os privilégios sejam anulados.

Assim, no caso de se desejar a proteção exclusivamente para uma determinada parte de um objeto que não pode ser destacada do conjunto que compõe a sua estrutura formal, esta deverá ser caracterizada no corpo do objeto, isto é, mesmo se tratando do interesse de proteção apenas para tal parte específica, o pedido terá que se referir a este objeto completo, em sua forma acabada, a qual será caracterizada através dos desenhos, e o título também deverá mencionar a configuração aplicada ao objeto como um todo.” (p.131) (...)

Por estas razões, o procedimento de exame diante desses casos deve ser aquele acima mencionado: a princípio conceder, por imposição da própria lei, e em seguida anular. Cabe ao requerente entender e assimilar esse aspecto legal que, no caso de desenho industrial, não é prevista a proteção para partes de objetos, tal como é previsto para a patente de Modelo de Utilidade, em cujo conceito o legislador fez questão de destacar textualmente a possibilidade de proteção para as partes dos objetos, o que não foi feito no caso do desenho industrial, cujo conceito só contempla o objeto em sua forma completa como um todo." (pp. 132-133)

$\mathrm{Na}$ verdade, a posição de Frederico Cunha, que encontrou eco no magistério de Newton Silveira ${ }^{38}$, tem razões ponderáveis, como se viu na análise acima. Apenas não se ajustam - no estender deste subscritor - ao sistema jurídico brasileiro vigente.

\section{- Um interpretação isolada na doutrina e nos precedentes}

Percorrendo a literatura pátria que interpreta o mesmo dispositivo ${ }^{39}$, verificase a o relativo isolamento da interpretação acima, em face de um quase total

38 Note-se, porém, que SILVEIRA, Newton, O abuso das montadoras face às fabricantes independentes de autopeças, Revista Eletrônica do IBPI Sobre a questão das peças de reposição must-match, Edição Especial, Janeiro de 2010, disponível em: http://www.wogf4yv1u.homepage.t-online.de/media/b1f03417495d4142ffff831aac144220.pdf, visitada em 29/1/2013, transcreve a citação acima. A publicação, para a qual este subscritor colaborou com o artigo A proteção dos mercados secundários no direito da propriedade intelectual no Brasil, discute aspectos relativos ao uso dos desenhos industriais em mercado de peças de reposição.

39 Vide ACQUAVIVA, Marcus Cláudio. Nova lei da propriedade industrial anotada. São Paulo: Editora Jurídica Brasileira, 1996. CERQUEIRA, João da Gama. Tratado da propriedade industrial-volume II- TOMO I- Parte II- Dos privilégios de invenção, dos modelos de utilidade e dos desenhos e modelos industriais. Rio de Janeiro: Lumen Juris Editora, 2010. CERQUEIRA, João da Gama. Tratado da propriedade industrial-volume I- parte I- Da propriedade e do objeto dos direitos. Rio de Janeiro: Lumen Juris Editora, 2010 . DANNEMANN, SIEMSEN, BIGLER \& IPANEMA MOREIA(cord.). Comentários à lei da propriedade industrial e correlatos. Rio de Janeiro: Renovar, 2001. DOMINGUES, Douglas Gabriel. Comentários à lei da propriedade industrial. Rio de Janeiro: Editora Forense, 2009. FURTADO, Lucas Rocha. Sistema de propriedade industrial no direito brasileiro. Brasília-DF: Brasília Jurídica, 1996. LOBO, Thomaz Thedim. Introdução à nova lei de propriedade industrial lei no 9279/96. São Paulo: Editora Atlas, 1997. MIRANDA, Pontes de. Tratado de direito privado. Parte especial TOMO XVI. São Paulo: Editora Revista dos Tribunais, 1983. MUJALLI, Walter Brasil. A propriedade industrial- Nova Lei de Patentes. São Paulo: Led Editora de Direito, 1997. PAES, P. R. Tavares. Nova lei da propriedade industrial. São Paulo: Editora Revista dos Tribunais, 1996. SANTOS, Ozéias J. Marcas e patentes, propriedade industrial. São Paulo: Lex Editoras, 2001. $2^{\mathrm{a}}$ ed. SOARES, José Carlos Tinoco. 
silêncio sobre tal requisito na literatura. Com efeito, o silêncio só não é total por se encontrarem posições em sentido diverso:

Relacionado ao tópico das características funcionais, as partes de objetos são componentes individuais de um produto complexo que é composto de múltiplos componentes "susceptiveis de serem dele retirados para desmontar e nele recolocados para montar novamente" 40 A Diretiva Europeia prevê proteção para partes de objetos desde que a parte componente seja visivel durante o uso do artigo e possa ser substituída quando o produto complexo for reparado. Partes componentes não visiveis, bem como as partes que têm seus desenhos ditados por aspectos funcionais e são caracterizadas como "must-fit", não podem ser protegidas. Similarmente, no Japão, partes funcionais são excluídas da proteção. Quanto ao Brasil, como será tratado no item II a seguir, essas partes de objetos podem ser registradas e protegidas, desde que sejam fabricadas e vendidas separadamente e a parte do objeto possa ser identificada separada do corpo do objeto principal. A forma da parte deve ser completamente definida ou acabada.

Nos EUA, as partes podem ser protegidas desde que sejam consideradas não funcionais.

Portanto, apesar de haver restrições de algumas legislações nacionais, mas considerando que o desenho industrial está relacionado diretamente à aparência do produto ou objeto, que na maioria das vezes é obtida através das características funcionais do mesmo, esses aspectos visuais ditados pela função técnica não deveriam ser considerados obstáculos para a proteção do referido desenho. O mesmo raciocínio deveria ser estendido para proteção das partes dos objetos $\mathbf{4 1}$.

E, mais adiante no mesmo texto:

Em princípio, a Lei Brasileira de Propriedade Industrial admite a proteção de partes destacáveis ou partes componentes de objetos, por não tratar expressamente da não registrabilidade de partes de objetos. Portanto, uma parte pode ser objeto de proteção uma vez atendidos os requisitos legais.

Basicamente, a principal diferença entre partes destacáveis e partes componentes é que a maioria dos casos de partes componentes diz respeito a partes do corpo principal do objeto e que não podem ser

Código da propriedade industrial. São Paulo: Editora Resenha Tributária, 1974. SOARES, José Carlos Tinoco. Lei de patentes, marcas e direitos conexos. São Paulo: Editora Revista dos Tribunais, 1997. TAVARES, Marcio Ney. Propriedade industrial: manual prático e legislação. Rio de Janeiro: Editora Esplanada, 2001, além de toda demais literatura mencionada neste estudo.

41 DI BLASI, Gabriel. Questões atuais na proteção dos desenhos industriais. In Revista da ABPI 93. Març/Abr 2008. P. 3-6 
substituídas por uma nova, embora possa ser produzida separadamente.

A parte destacável do objeto é registrável se feita e vendida separadamente e quando pode ser identificada separada do corpo do objeto principal. A forma da parte deve ser completa e definida ou acabada. Entretanto, se um objeto é parte de um desenho e não pode ser separado do corpo do objeto, ou se o componente é integral na fabricação do objeto principal, a parte componente não pode ser protegida como um desenho brasileiro. Exemplos de partes destacáveis que são protegidas por desenho industrial incluem peças de reposição de veículos, tais como o para choque, faróis, espelhos e retrovisores de automóveis, ou a cabeça de lâminas de um aparelho de barbear. Para ser considerada parte destacável e ser protegida pelo registro, torna-se necessário avaliar se aquela parte pode ser produzida ou comercializada separadamente, ou se pode ser aplicada ou instalada ao objeto principal manualmente pelo usuário sem ser considerada uma parte integral do processo industrial 42".

Finalmente:

Portanto, o Brasil adota a posição de que partes de objetos que sejam uma parte integral do processo industrial não podem ser protegidas. Quanto às partes destacáveis, elas só são registráveis se fabricadas e vendidas separadamente e quando podem ser identificadas separadas do corpo do objeto principal. Para ambos os casos, a forma da parte deve ser completamente definida ou acabada. Em casos complexos, o INPI aplicará uma análise prática para determinar se o registro de desenho se justifica nos parâmetros legais.

Assim, no Brasil, o registro e proteção da parte destacável e componente de um objeto estão disponíveis para os casos em que a parte tem características próprias ou pode ser identificada separada do objeto principal. Geralmente, isso significa que a parte é feita e vendida separadamente ou pode ser identificada ou separada do corpo do objeto principal.

Os precedentes judiciais ecoam a noção de que partes de um produto complexo são, efetivamente, protegidas:
(Tampa)
"As variações apostas pelo apelante em sua tampa [registro de desenho industrial $n^{\circ}$ DI 6402613-2,

42 [Nota do original] CUNHA, Frederico Carlos. A proteção legal do design: propriedade industrial. Rio de Janeiro, Lucerna. 2000, p. 129-130. 
intitulado "configuração aplicada em conjunto de tampas de tomada para piso"] são efetivamente de pequeno alcance, considerando o design do modelo como um todo, não chegando a implicar suficiente distintividade a possibilitar o registro pretendido. É certo que a combinação de elementos conhecidos por vezes resulta em composição distinta e nova, capaz de ensejar um registro, porém, no caso em tela, o produto final é bastante assemelhado aos modelos impeditivos, confundindo-se, a toda evidência, com os mesmos, como bem observado pelo INPI". Tribunal Regional Federal da $2^{\mathrm{a}}$ Região, $2^{\mathrm{a}}$ Turma Especializada, Des. Liliane Roriz, AC 2004.51.01.506176-3, DJ 26.02.2009.

(Puxadores de móveis em geral)

"Com efeito, a proteção a apelante restringe-se ao desenho industrial registrado não podendo impedir o uso de outros puxadores com desenhos e técnicas distintas. (...) Logo, a utilização de desenho distinto daquele registrado pela autora no INPI, com técnicas diferenciadas de aplicação, seguindo tendências do ramo, ainda que tendo o mesmo objetivo, puxador para móveis em geral, não importa em violação à propriedade industrial." TJPR, AC 689.552-1, Sétima Câmara Civel do Tribunal de Justiça do Estado do Paraná, por unanimidade de votos, Des. Joatan Marcos De Carvalho, 14 de dezembro de 2010.

(Copos de liquidificadores)

"Ementa: Propriedade Industrial. Desenho industrial relativo a copos de liquidificadores, todos semelhantes, há várias décadas antes do registro do desenho pela agravada, em 2000, é suficiente para caracterizar o estado da técnica de que cogita o art. 96, § I o, da Lei $n^{\circ}$ 9279/96, por meio do qual não pode ser considerado novos o que já se tenha tornado acessivel ao público antes do registro. Exame do mérito pelo INPI que não impede a prestação jurisdicional com o reconhecimento do estado da técnica, até porque o órgão estatal somente pesquisa outros registros e no caso concreto e mais abrangente está claro que outras empresas, inclusive a ré, fabricam e vendem copos de liquidificadores semelhantes ao da autora. Improcedência acertada. Precedentes do STJ. Recurso improvido.

TJSP, AC 459.642-4/7, Quarta Câmara de Direito Privado do Tribunal de Justiça do Estado de São Paulo, Maia da Cunha, 21 de fevereiro de 2008.

(Empunhadura de tampas de panela) 
"Ementa: AÇÃO DE OBRIGAÇÃO DE NÃO FAZER C/C INDENIZAÇÃO POR DANOS MATERIAIS E MORAIS Hipótese em que a ré fabrica e comercializa, sem autorização, empunhaduras de tampas de panela consistentes em cópia fiel do design protegido pelo desenho industrial de titularidade da $1^{\text {a }}$ autora Alegação de nulidade do registro, pela falta do requisito novidade Concessão de registro no INPI que não depende de exame de mérito (...)

TJSP, AC 9186043-82.2006.8.26.0000, Primeira Câmara de Direito Privado do Tribunal de Justiça do Estado de São Paulo, Rui Cascaldi, 22 de novembro de 2011.

(Mais tampas)

"Em momento algum foi demonstrado nos autos que a ré-recorrida fabricasse tampas plásticas com as características ou mesmo reprodução integral daquelas cuja patente pretende ao autor-recorrente. Aliás, a inicial refere-se principalmente a comercialização desses produtos pela recorrida e tal fato por ela não é negado. Adquire-as de outros fabricantes e agrega detalhes que, basicamente, não alteram as características do produto, e comercializaas"

TJSP. Ac 9253513-62.2008.8.26.0000, 4ª Câmara de Direito Privado do Tribunal de Justiça de São Paulo, Des. Fábio Quadros, 19 de janeiro de 2012.

Perquirindo a atuação administrativa do INPI, entre aos 477 pedidos e registro relativos a "cabo" de alguma coisa (escovas de dentes, panelas, etc.), veja-se a exigência ao pedido de registro DI7002025-6, depositado em 17/05/2010, com o título "configuração aplicada em cabo para aparelho de barbear":

- Cancelar as figuras. - Reapresentar as figuras ilustrando somente o objeto (cabo), sem revelar a cabeça do aparelho em linhas tracejadas.

\section{- Da interpretação que entendo adequada}

Considerados os subsídios da literatura e dos precedentes, passemos a oferecer qual nosso entendimento quanto ao quesito em análise.

Do meios de interpretação aplicáveis

Para nos manter na coerência do que vimos há muito entendendo, vale aqui repetir o que dissemos sobre a interpretação devida às normas da propriedade intelectual, em nosso Tratado, vol. II, cap. VI:

[ 15 ] § 2. 2. - A questão constitucional 
(...) Vale aqui lembrar o que já dissemos anteriormente, quanto à natureza das normas de patentes 43:

Dessas manifestações da regra de balanceamento de interesses se pode depreender que a lei de patentes ou de direitos autorais não é um estatuto de proteção ao investimento - e nem dos criadores e inventores; não é um mecanismo de internacionalização do nosso direito nem um lábaro nacionalista; é e deve ser lida como um instrumento de medida e ponderação, uma proposta de um justo meio e assim interpretado. E no que desmesurar deste equilíbrio tenso e cuidadoso, está inconstitucional.

Dois óbvios resultados derivam da aplicação do princípio da razoabilidade: o primeiro é que, na formulação da lei ordinária que realiza o equilíbrio de interesses, essa deve - sob pena de inconstitucionalidade ou lesão de principio fundamental - realizar adequadamente o equilíbrio das tensões constitucionais; a segunda conseqüência é a de que a interpretação dos dispositivos que realizam os direitos de exclusiva deve balancear com igual perícia os interesses contrastantes.

Por exemplo, não se dará mais alcance ao conteúdo legal dos direitos de patente do que o estritamente imposto para cumprir a função do privilégio de estímulo ao investimento na mínima proporção para dar curso à satisfação de tais interesses. Vide o que diz a Suprema Corte dos Estados Unidos quanto à interpretação restritiva das reivindicações.

(...) O mesmo cunho de contenção e prudência se aplica à interpretação das leis de propriedade intelectual. Quando se interpreta a norma ordinária singular há que se presumir que - salvo inconstitucionalidade - o texto legal já realizou o favorecimento que se deve ao investimento privado. Lex data, é momento de se interpretar a norma segundo os critérios próprios ao caso, razoável e equilibradamente.

Este equilíbrio surge à interpretação das normas segundo os critérios da proteção da liberdade de iniciativa em face da restrição imposta pela propriedade intelectual; e segundo o critério tradicional da interpretação contida da norma excepcional.

Diogo de Figueiredo, ao pronunciar-se sobre o tema, avalia que:

"os princípios que definem liberdades preferem aos que as condicionam ou restringem; e os que atribuem poderes ao Estado, cedem aos que reservam poderes

43 Bases Constitucionais da Propriedade Intelectual, Publicado na Revista da ABPI de Agosto de 2002. 
aos indivíduos, e os que reforçam a ordem espontânea têm preferência sobre os que a excepcionam" (grifos da transcrição).

A liberdade, obviamente, é de iniciativa e de informação, coarctadas pelos privilégios e direitos de exclusiva. A ordem espontânea é o do fluxo livre das ideias e das criações, e da disseminação da tecnologia. $\mathrm{O}$ ato do Estado que cumpre estabelecer peias é o da concessão do direito excepcional da propriedade intelectual.

E, como ensina Carlos Maximiliano:

"O Código Civil [de 1916] explicitamente consolidou o preceito clássico Exceptiones sunt strictissimae interpretationis ("interpretam-se as exceções estritissimamente") no art. $6^{\circ}$ da antiga Introdução, assim concebido: 'A lei que abre exceção a regras gerais, ou restringe direitos, só abrange os casos que especifica'", dispositivo hoje consagrado no art. $2^{\circ}, \S$ $2^{\circ}$, da vigente Lei de Introdução ao Código Civil [de 1916].

Continua o pensamento afirmando que igual orientação deve ser adotada para aquelas normas que visem à concessão de um privilégio a determinadas pessoas, pois: "o monopólio deve ser plenamente provado, não se presume; e nos casos duvidosos, quando aplicados os processo de Hermenêutica, a verdade não ressalta nítida, interpreta-se o instrumento de outorga oficial contra o beneficiado e a favor do Governo e do público".

Assim, não se deve interpretar as normas da Lei 9.279/96 nem contra, nem a favor do titular ou depositante, mas da forma mais harmônica com as funções e princípios que as normas deve, expressar, e com respeito às escolhas políticas que o processo legislativo elegeu como relevantes.

\section{Das escolhas que a legislação em vigor fez}

Para entendermos o contexto da atual legislação brasileira, vale considerar como, na história legislativa, a questão dos produtos complexos foi tratada.

\begin{tabular}{|c|c|c|c|c|}
\hline $\begin{array}{l}\text { Regulamento } \\
\text { a que se refere } \\
\text { o Decreto N. } \\
24.507 \text {, de } 29 \\
\text { de Junho de } \\
1934\end{array}$ & CPI/45 & CPI/ 67 & CPI/ 69 & $\begin{array}{l}\mathrm{CPI} / 71 \\
\mathrm{CPI} / 96\end{array}$ \\
\hline $\begin{array}{lr}\text { Art. } & 12^{\circ} . \\
\text { Sempre que } & \text { o }\end{array}$ & $\begin{array}{lll}\text { Art. } \quad 38 & - \\
\text { Sempre que } & \text { o }\end{array}$ & $\begin{array}{l}\text { Art. } \quad 11 \quad- \\
\text { Parágrafo }\end{array}$ & $\begin{array}{ll}\text { Art. } \quad 11 & - \\
\text { Parágrafo } & \end{array}$ & $\begin{array}{l}\text { Nenhuma } \\
\text { disposição }\end{array}$ \\
\hline
\end{tabular}




\begin{tabular}{|c|c|c|c|}
\hline $\begin{array}{l}\text { depositante } \\
\text { quiser garantir } \\
\text { isoladamente } \\
\text { qualquer } \\
\text { particularidade } \\
\text { de um } \\
\text { desenho ou } \\
\text { modelo } \\
\text { complexo, } \\
\text { poderá fazê-lo } \\
\text { mediante } \\
\text { pedido em } \\
\text { separado. }\end{array}$ & $\begin{array}{l}\text { depositante } \\
\text { quiser garantir, } \\
\text { isoladamente, } \\
\text { qualquer } \\
\text { particularidade } \\
\text { de um desenho } \\
\text { ou modêlo } \\
\text { complexo, } \\
\text { poderá fazê-lo } \\
\text { mediante } \\
\text { pedido em } \\
\text { separado }{ }^{44} \text {. }\end{array}$ & $\begin{array}{l}\text { único. } \\
\text { Considerar-se- } \\
\text { ão como um } \\
\text { só modêlo ou } \\
\text { um só } \\
\text { desenho os } \\
\text { que, embora } \\
\text { compostos de } \\
\text { várias partes, } \\
\text { constituam } \\
\text { um todo ou } \\
\text { um conjunto } \\
\text { característico. }\end{array}$ & $\begin{array}{l}\text { único. } \\
\text { Considerar- } \\
\text { se-ão como } \\
\text { um só } \\
\text { modêlo ou } \\
\text { um só } \\
\text { desenho os } \\
\text { que, embora } \\
\text { compostos de } \\
\text { várias partes, } \\
\text { constituam } \\
\text { um todo ou } \\
\text { um conjunto } \\
\text { característico. }\end{array}$ \\
\hline
\end{tabular}

Assim é que - por óbvia escolha do legislador - não existe disposição específica na lei vigente, que cuide da hipótese de elementos singulares de um produto complexo. Há sim um dispositivo que fala da unidade da criação ${ }^{45}$, mas não da unitariedade desta. Ou seja, exige-se que em cada registro haja uma só criação ornamental, em até vinte variações; mas não se exige, nem se repele, que o produto sobre o qual se apõe o ornamento e suas variações seja um só e indivisível, ou que seja complexo.

A norma em vigor certamente não explicita a permissão de se proteger, separadamente, a "particularidade de um desenho ou modelo complexo", "mediante pedido em separado".

De outro lado, a vigente lei não contém dispositivos - como as normas anteriores -, dispondo que "considerar-se-ão como um só modelo ou um só desenho os que, embora compostos de várias partes, constituam um todo ou um conjunto característico". Ou seja, ela não proíbe, como as anteriores, que havendo um todo, ou mesmo se não havendo um todo, havendo um conjunto, conjunto este dotado de uma característica individualizadora, se possa ter proteção das várias partes.

\footnotetext{
44 RODRIGUES, Clóvis Costa. Concorrência desleal, Rio de Janeiro: Editoria Peixoto, 1945, p. 255 nota sobre o art. 38 da CPI/45 que, no caso de "as flores formam um desenho estilizado, inédito, que se sai do conjunto...neste caso ao autor é facultado proteger, além do conjunto do desenho, também o desenho da flor isoladamente, aplicado a tecidos".

45 Segundo o art. 104 do CPI/96, o pedido de registro de desenho industrial terá que se referir a um único objeto, permitida uma pluralidade de variações (até um máximo de vinte) desde que se destinem ao mesmo propósito e guardem entre si a mesma característica distintiva preponderante, limitado cada pedido ao máximo de vinte variações. Tem-se aí o paralelo das noções de unidade de invenção e de conceito inventivo, dos quais já se tratou ao referirmo-nos às patentes.
} 
Da leitura de que a lei proíbe proteção ornamental de parte de um produto

Assim é que não parece adequada a leitura de que se possa ler, na lei em vigor, uma vedação da proteção ornamental de parte de objetos. Com efeito, ao afirmar que o artigo 95 da Lei

...define como desenho industrial a forma plástica ornamental de um objeto e, portanto, não prevê proteção para partes de objetos...

o autor citado faz uma distinção que a lei não fez. Não diz a lei que tal objeto deva ser um objeto unitário; quem repele, neste passo, a proteção dos ornamentos apostos a um objeto complexo é o autor. Como já indicamos, ao percorrer os precedentes judiciais, é uma distinção que faz isoladamente.

Raciocina o autor que, por o dispositivo sobre modelos de utilidade referir-se ao "objeto de uso prático, ou parte deste", a inexistência deste dizer no dispositivo sobre desenhos impõem uma unitariedade inescapável.

Examinemos o exercício lógico, e continuemos a mesma prática. Diz ainda a seção da Lei relativa aos modelos industriais:

Art. 23. O pedido de patente de modelo de utilidade terá de se referir a um único modelo principal, que poderá incluir uma pluralidade de elementos distintos, adicionais ou variantes construtivas ou configurativas, desde que mantida a unidade técnicofuncional e corporal do objeto.

Assim, apliquemos o mesmo critério, qual seja, o que está expresso em uma normativa, mas silente na outra, se presume não aplicável nesta outra. Segundo tal critério, é de se concluir que para os desenhos não se exige que se mantenha a unidade técnico-funcional e corporal do objeto ${ }^{46}$. Esta conclusão é, obviamente, tão imprecisa e descabida quanto a que não se protegem, em nosso direito, partes de um produto.

Abandonemos, assim, uma extrapolação, por negativa, do que diz a normativa de modelos de utilidade para perquirir o próprio subsistema das criações ornamentais. $\mathrm{Na}$ verdade, comparemos o art. 23 da Lei com a norma correspondente, no capítulo dos desenhos industriais:

Art. 104. O pedido de registro de desenho industrial terá que se referir a um único objeto, permitida uma pluralidade de variações, desde que se destinem ao

\footnotetext{
46 Para manter clara a distinção anteriormente feita, os art. 23 e 104 prescrevem unidade de invenção, e não unitariedade do objeto. No entanto, para fazê-lo, se utilizam do referencial do objeto físico, pois tanto o modelo de utilidade quanto o desenho industrial são criações que se referem necessariamente um corpo tangível. No tocante às patentes de invenção, que não só compreendem corpos físicos, mas processos e outras intangibilidades, a redação é notavelmente mais abstrata: "Art. 22. O pedido de patente de invenção terá de se referir a uma única invenção ou a um grupo de invenções inter-relacionadas de maneira a compreenderem um único conceito inventivo".
} 

mesmo propósito e guardem entre si a mesma
característica distintiva preponderante, limitado cada
pedido ao máximo de 20 (vinte) variações.

Há sim uma exigência de unidade, mas de propósito e da característica distintiva preponderante. Dupla exigência, mas de forma alguma imposição de unidade técnico-funcional e corporal do objeto. Na verdade, o art. 104 ilumina a natureza do tratamento dos objetos aos quais são apostos os desenhos industriais a lei brasileira.

Compatível com os critérios indicados acima que as normas estrangeiras usam para definir quando não serão protegidas a partes de um produto, nossa lei diz que não se admite proteção separada para o que - do ponto de vista da criação ornamental - não poderá ser cindido quando haja prejuízo do efeito tutelado. Por exemplo, se faltarem novidade e originalidade nas partes singulares, ainda que subsistam no todo.

\section{Um retorno às funções do desenho industrial}

Como se viu, protegem-se com direitos exclusivos as criações ornamentais, e com isso se estimula a geração de produtos industriais agradáveis à vista e atraentes ao consumo, essencialmente como uma forma de diferenciação de produtos. Os poderes que o direito brasileiro vincula ao estímulo de tais propósitos - uma exclusividade, ou monopólio instrumental -, deve propiciar a esses objetivos, mas não serem usados de maneira disfuncional, ou seja, de maneira a exceder o limite externo de tais poderes, ou usá-los para fins distintos da função que os justifica.

A interpretação que se deduz do art. 104, de que haja unidade sempre que haja o mesmo propósito ${ }^{47}$ e uma unidade ornamental (característica distintiva predominante) parece-nos inteiramente compatível com tal função. O que se diz das variações é estruturalmente aplicável aos elementos destacáveis de um objeto ornamental.

Mais ainda, tal dicção da lei não se opõe, antes se integra com outros critérios mais lógicos do que jurídicos, que presumem a possibilidade de proteção separada de partes de um produto. Com efeito, o sistema brasileiro não se rejeita os outros critérios que, nos outros sistema legais citados, também impedem a proteção separada de partes de um produto, para evitar a disfuncionalidade da proteção:

\footnotetext{
47 A noção de propósito, neste contexto, resulta da acessoriedade do ornamento e o fato de que a novidade e objeto de tutela não esteja no ornamento em si, mas nele enquanto aplicado num produto industrial. É o que já denominamos de novidade relacional. Assim, o art. 104 da Lei exige que, para haver unidade de desenho, cada variação deve aplicar-se ao mesmo produto industrial, e mais, para o mesmo ato ornamental.
} 
(a) não cabe proteger separadamente parcelas de um produto que resulte de uma industrialização unitária: uma garrafa cujo gargalo só dela se separe se dela for quebrada;

(b) não cabe proteger separadamente elementos de um produto que, ainda que fisicamente destacáveis sem quebra, nunca são oferecidos ao público senão na forma íntegra ${ }^{48}$.

(c)Ao que se acrescem as exigências de que o elemento destacável não só seja por si só suscetível de proteção (novidade, originalidade, não tecnicidade, etc.) mas que, ao se reintegrado desempenhe uma função ornamental (visibilidade) ${ }^{49}$.

Com isso se faz aplicável, de forma consequente e logicamente integrada, a fórmula deduzida das formulações dos outros sistemas jurídicos.

\section{Como o direito brasileiro protege as criações ornamentais de produtos}

As partes de um produto são suscetíveis de proteção:

1. sempre que tal produto seja composto de múltiplos componentes substituíveis, que possam ser desmontados e remontados; provavelmente tal fórmula compreenderá a exigência de que as partes sejam fabricadas separadamente, mas valeria acrescer -

2. que as partes sejam disponíveis ao público separadamente. Cabe exigir ainda

3. que cada parte desempenhe uma função visível (daí, ornamental ou potencialmente ornamental) quando remontada no produto complexo;

4. E que, cada uma de tais partes satisfaça, por si só, todos os requisitos legais para proteção separada.

Tal fórmula parece compatível com o direito brasileiro, atendendo os requisitos literais e sistemáticos do sistema legal, sem aumentar desrazoável, ou disfuncionalmente, os ônus dos depositantes.

É, ademais, compatível com os precedentes e o estudo doutrinário que citamos acima.

\footnotetext{
48 Lembrando Pouillet, de sua publicação de 1905: o que o desenho industrial, em sua modalidade ornamental, cria é uma inovação comercial. Assim, esta característica justifica que se coloque como requisito um fator extrínseco ao processo industrial como um requisito de direito. A parte que é ornamental e separada, mas que não exerce a função de diferenciação de produtos no âmbito estritamente da relação com o público não é funcional dentro da hipótese de proteção estudada.

49 Aqui se justifica a invocação de Isaías 48:12. A ideia de múltiplos corpos com uma única essência, repartida mas não esgarçada pela separação, de maneira que cada elemento continue ornamental de per si ainda que continuando ornamental no todo, se talvez desusado em direito, encontra talvez o mais fácil exemplo na doutrina da trindade.
} 


\section{O problema que tal fórmula não resolve}

Claramente tal entendimento não se propõe a resolver, criando uma vedação que não existe no texto legal, o sensível problema das peças de reposição must match.

Sem dúvida tal questão exige uma solução de direito, seja regulatória, seja legislativa ${ }^{50}$, seja por via da aplicação das limitações razoáveis já constantes do nossos sistema jurídico ${ }^{51}$.

Mas, pelos motivos que expus na parte inicial deste estudo, não existindo na lei brasileira uma proibição abstrata e genérica de registro de desenhos industriais de partes de produtos complexos, não cabe ao intérprete suprir a política pública necessária com uma proibição de origem estritamente pessoal, que não foi assim homologada pelo processo democrático da mutação legislativa.

O fato de que outros sistemas jurídicos introduziram tal vedação, através do processo legislativo regular, resistido e complexo como ocorre nas democracias, nos aponta tanto para os objetivos quanto para os métodos legais para alcança-los.

\section{Um elemento ornamentado, destacado, se torna funcional?}

O segundo quesito, como já mencionamos, é se os objetos componentes de um todo maior ao serem comercializados separadamente, passam por isso a terem características exclusivamente técnicas.

Uma primeira ponderação, antes de entrar na resposta, é que o pressuposto de uma peşa de um todo ter proteção separada é que ela seja suscetível de ser vendida separadamente. Quem propôs essa conclusão confundiu um requisito de proteção com uma exclusão.

\section{- A simples resposta deste quesito}

Com o respeito devido a toda opinião, a resposta a esse quesito é de tal simplicidade que nem mereceria atenção.

Como notamos acima, o pressuposto necessário para que se possa proteger, separadamente, partes de um produto complexo é que cada uma delas satisfaça, isoladamente, todos os requisitos legais da proteção.

Note-se que isso resulta, necessariamente, da lógica do sistema de proteção dos desenhos industriais, que apura a novidade não do ornamento em si mesmo, mas de sua aplicação. Em outro estudo, assim lembramos:

\footnotetext{
${ }^{50}$ Como, por exemplo, a constante da nossa proposta de alteração legislativa anteriormente citada.

51 Como a por nós proposta em BARBOSA, Denis Borges, A proteção dos mercados secundários no direito da propriedade intelectual no Brasil, acima citado.
} 
Enquanto os requisitos à definição do estado da técnica relevante sejam uniformes em face das patentes e dos desenhos industriais, há uma peculiaridade nestes últimos no tocante ao elemento para o qual se apura a novidade.

Com efeito, o desenho é uma criação ornamental e acessória a um produto industrial; assim, é ao ato de aposição do desenho ao produto que se elege como relevante para determinar a novidade, ou não. Como também nota Newton Silveira:

Pode-se falar, assim, em uma novidade relativa, consistindo não na forma abstratamente considerada, mas na forma efetivamente utilizada como modelo $\mathbf{5 2}$.

Ainda que nos preocupe essa utilização da fórmula "novidade relativa" (pois, como vimos, para efeitos de estado da técnica, a novidade é sempre absoluta), adotemos a observação, mas denominando o fenômeno novidade relacional.

Lembra ainda o autor:

A novidade de um modelo ou desenho pode consistir na composição do conjunto, mesmo que suas partes sejam conhecidas. Segundo Pouillet, tais criações quando não despertam nenhum sentimento estético, satisfazendo apenas ao gosto da moda, somente podem ser protegidas pela lei de desenhos e modelos, caso contrário entram no dominio da propriedade artistica".

Ou seja, pelo fato de haver proteção ao todo, não se presume a proteção da parte; as partes podem ser desprotegidas, sem que isso retire a protectibilidade do todo.

O silogismo se completa: mas as partes podem ser protegidas, se por si só atendem os requisitos legais de proteção.

Assim, não é simplesmente por serem partes de um objeto que elas deixam de ser dignas de proteção, e nem pelo fato de cada uma delas ser parte de um todo, que por sua vez é protegido, que faz delas protegidas individualmente ${ }^{53}$.

\footnotetext{
52 Direito do Autor no Desenho Industrial, ed. 1982, pp. 65.

53 De outro lado, não se imagine que a cópia ou contrafação parcial de uma parte de um produto complexo seja necessariamente livre, pelo fato de que ela, por si só, seja do domínio comum. Ela será, sim, isenta do direito exclusivo, que só atinge o todo. Mas, ainda que estruturada numa forma similar ao do sistema de patentes, a proteção dos desenhos industriais, sendo relativa a uma criação comercial, é suscetível de induzir confusão do público quanto à origem dos produtos. Assim, se for demonstrada a efetiva confusão da parte, no que evocar pars pro toto a criação complexa, poderá, nestes termos restritos, e enquanto a confusão persistir, ser objeto de repressão à concorrência desleal. Veja-se a este propósito os precedentes judiciais colecionados em nosso A proteção dos mercados secundários no direito da propriedade intelectual no Brasil, cit., quanto aos limites do direito de os fabricantes de peça de reposição indicarem a marca do fabricante da peça reposta, que exigem sempre que tais elementos sejam claramente assinalados para evitar qualquer engano quanto à origem ou autorização dos produtos ou serviços.
} 
Como quase tudo em direito, esse problema já encontrou revisão judicial ${ }^{54}$, com a seguinte conclusão sancionada pela corte suprema francesa:

"Cada parte da carrosseria exprime uma parte do pensamento do criador do conjunto da carroseria e a proteção legal, que cobre o todo, também incide sobre cada um de seus componentes, caso contrário a proteção seria ilusória; é errado assimilar um elemento da carrosseria a uma peca destacada tendo apenas uma função técnica, porque se uma asa ou um capot satisfazem um requisito técnico, eles também contribuem para a estética global do modelo, uma vez que para uma determinada função, há tantas formas quanto a imaginação dos designers conseguem conceber".

\section{Da recente manifestação do TRF2}

Não exatamente seguindo nossa análise, mas no sentido geral de suas conclusões, nota-se o recente pronunciamento - por maioria - da $2^{\mathrm{a}}$. Turma do TRF2:

\footnotetext{
$54 \mathrm{O}$ trecho de Pollaud-Dullian nos economiza maior discussão deste tema: "Mais si le "design" de la carrosserie est nouveau et a un caractere propre et si la piece en question aussi, en dehors de ses éléments de raccordement, on voit mal pourquoi ce " design " pourrait être exploité sans licence par des tiers. La protection du tout devrait s'étendre aux parties [Dans le même sens : G. BONET, article cité, Prop. Intell. janvier 2003, p. 5]. Il y aurait, sinon, une réduction du droit exclusif sur les formes complexes au détriment de certaines entreprises et au profit d'autres, par hypothese moins innovantes ou moins créatives. Quant à soutenir que la portiere, le rétroviseur ou le pare-choc aurait un caractere exclusivement fonetionnel, cela suppose la démonstration de l'absence de tout arbitraire dans l'ensemble et dans la partie et non pas de ce que la pièce fait partie d'un ensemble. Cela impliquerait que la forme soit liée à une fonction d'intégration de cet ensemble, du seul fait qu'elle lui est complémentaire [Paris, 9 mai 2003, PIBD 2003 n. 773-1Il-526, Prop. lntell. 2003, p. 400, obs. P. de CANDÉ (" il ne suffit pas de prétendre que cette forme trouve sa seule et unique raison d'être dans la forme de l"appareil distributeur [de savon liquide] dans lequelle flacon-recharge vient s'insérer, le distributeur étant lui-même protégé à titre de modele et aucun élément n'établissant que le flacon ne pourrait être utilisé en dehors du distributeur " $\}$. Du reste, rien n'empêche d'installer sur une voiture d'un modele donné, un pare-choc qui s'y adapte techniquement mais n'a pas le même " design " que ceux de la marque, sinon des arguments d'ordre esthétique et commercial mais nullement des raisons fonctionnelles ... Et si ce pare-choc est moins cher et plus solide, le consommateur pourrait fort bien le préférer à ceux d'origine. Comparez: J. PASSA, Traité, n. 715.], ce qui inverse le raisonnement et donne à la forme un rôle réducteur, en vidant le droit exclusif de sa substance [De proche en proche, ce sont alors tous les éléments qui, assemblés, font l'apparence du véhicule, qui seraient privés de protection et, en fin de compte, la carrosserie elle-même, le droit exclusif ne valant plus que pour le premier assemblage et disparaissant ensuite]. La Cour d'appel de Dijon avait statué sur ce point sous l'empire de la loi du 14 juillet 1909 [Dijon, 12 janvier 1990 "Maxicar c. Renault ", PIBD 1990 n. 478-IlI-342.] et le pourvoi dirigé contre son arrêt fut rejeté par la Chambre criminelle le 6 juin 1991[Casso crim., 6 juin 1991, " Maxicar c. Renault ", PIBD 1991 n. 511-III-695. ]. Celle-ei estima que la cour d'appel avait fait une exacte application de la loi du 14 juillet 1909 en énonçant que: "chaque élément de la carrosserie exprime une part de la pensée du créateur de l'ensemble de la carrosserie et que la protection légale, qui s'attache au tout, s'attache également à chacun de ses éléments constitutifs, faute de quoi cette protection serait illusoire ; [et] qu'il est inopérant d'assimiler un élément de carrosserie à une piêce détachée ayant seulement une fonction technique, car si une aile ou un capot répondent à un besoin technique, ils participent aussi à l'esthétique générale du modele, puisque, pour une fonction déterminée, il existe autant de formes que l'imagination des créateurs est susceptible d'en concevoir ". Cette solution reste valable [En ce sens : G. BONET, article précité, Prop. Intell. juillet 2003, p. 10.]." DULIAN, Frédéric Pollaud. Propriété Intellectuelle - La Propriété Industrielle. Ed. Economica. Paris. 2011. P. 523-524 e 541-543
} 
"Portanto, não são passíveis de registro as formas ornamentais desprovidas de novidade, originalidade e/ou aplicação industrial, ou àquelas que esbarrem nas hipóteses do artigo 100, incisos I e II da Lei da Propriedade Industrial. Ao apreciar o caso, o Magistrado a quo entendeu que "o design de faróis e parachoques estão atrelados preponderantemente à função técnica, tendo em vista que não são admitidas formas que não satisfaçam sua finalidade precípua".

Note-se que as peças de automóvel, embora possuam sua forma considerada técnica ou funcional, para atender às necessidades impostas à fabricação do veículo, também podem possuir características ornamentais diferenciadas, com visuais próprios, de acordo com o design utilizado no modelo de cada automóvel, sendo passível seu registro como desenho industrial.

Caso assim não o fosse, todos as peças de automóvel, especificamente, neste caso, os faróis e os parachoques dos carros seriam todos iguais. Assim, embora as peças e acessórios automotivos sejam partes do produto "automóvel", constituem cada um deles um objeto em si. De fato, o consumidor, na hipótese de um sinistro, pode se dirigir a uma concessionária autorizada e comprar, separadamente, um farol, ou espelho retrovisor, ou uma calota, ou uma roda etc., ou seja, pode comprar todas as partes independentes do automóvel. (...)

Portanto, verifica-se que os designs dos faróis e parachoques protegidos pelos registros de desenho industrial obtidos pelo FORD junto ao INPI, embora atendam a finalidade precípua de iluminar e reduzir o impacto de eventuais colisões, respectivamente, possuem características ornamentais diferenciadas, com visuais próprios, sendo passível seu registro como desenho industrial, não havendo que se falar em violação ao disposto no art. 100, inciso II da LPI. Tribunal Regional Federal da $2^{\mathrm{a}}$ Região, $2^{\mathrm{a}}$ Turma Especializada, Voto Vencedor do Des. Marcelo Pereira, AC 2010.51.01.809326-0, DJ 10.12.2013.

Publicado no dia 26/02/2014

Recebido no dia 15/02/2014

Aprovado no dia 20/02/2014 